\title{
A articulação entre saber e poder em tempos de Covid-19: uma reflexão a partir de Foucault
}

\author{
The articulation between knowledge and power in Covid-19 times: a reflection from Foucault
}

Ricardo Max Lima Cavalcante ${ }^{1}$

\author{
1 Universidade Federal de Alagoas \\ E-mail: maxcavalcantephilos@gmail.com Orcid: http://orcid.org/0000-0002-2617-3976 Lattes: http://lattes.cnpq.br/3264684786743107
}

RESUMO: O objetivo deste artigo é resgatar da obra do filósofo francês Michel Foucault (1926-1984) reflexões acerca da articulação entre o saber médico e as políticas públicas de saúde como a que estamos vivendo em todo o mundo, por exemplo, o isolamento social, a quarentena ou o lockdown com o intuito de reduzir o avanço da pandemia do Covid-19 no ano de 2020. Para isso, primeiramente faremos uma explanação da passagem da medicina baseada na História Natural para a medicina baseada na Biologia na passagem do século XVIII para o XIX exposta na obra O nascimento da clínica. Em seguida, devemos demonstrar que esta não é a primeira epidemia que a humanidade enfrenta e, de acordo com alguns dos próprios exemplos mencionados por Foucault, como historicamente a medicina moderna tomou medidas semelhantes a que estamos tomando hoje em dia, criando assim uma estratégia de gerenciamento da ordem do saber médico e da ordem organizacional e política da vida dos indivíduos que compõem a população de um Estado, o que Foucault denominará de biopolítica.

Palavras-chaves: Covid-19 - Foucault - Biopolítica.

ABSTRACT: The aim of this article is to recover from the work of the French philosopher Michel Foucault (1926-1984) reflections on the articulation between medical knowledge and public health policies such as the one we are seeing all over the world, for example, social isolation, quarantine or lockdown in order to slow the progress of the Covid-19 pandemic in 2020. For this, we will first make an explanation of the transition from medicine based on Natural History to medicine based on Biology in the transition from the 18th to the 19th century exposed in the work The birth of the clinic. Next, we must demonstrate that this is not the first epidemic that humanity faces and, according to some of the examples mentioned by Foucault, how historically modern medicine has taken measures similar to what we are taking today, thus creating a strategy of management of the order of medical knowledge and the organizational and political order of life of the individuals that make up the population of a state, which Foucault will call biopolitics.

Keywords: Covid-19 - Foucault - Biopolitics.

\section{INTRODUÇÃO}

Desde que a humanidade foi pega de surpresa com esta pandemia de Covid-19, causada pelo vírus SARS-COV-2, sentimos a necessidade de resgatar as reflexões feitas por Michel Foucault (1926-1984) na segunda metade do século XX acerca da medicina, dos poderes do Estado e das instituições disciplinares na Modernidade. Fazendo assim, no seu ponto de vista, que haja uma articulação entre o saber e o poder, no qual um justifica o outro e vice-versa. A articulação a qual nos referimos cria medidas sanitárias, higiênicas e de confinamento social, fundando assim uma medicina-política. 
Primeiramente, deve-se compreender qual a noção de poder de Foucault, pois para ele, não se pode definir "poder" como um objeto que se toma pelas mãos e que uma hora se tem e que pode ser tomada outra vez, e sim uma relação entre instituições, indivíduos, Estado, classes econômicas etc. Foucault dá o nome destas relações de microfísica do poder: "Onde há poder, ele se exerce. Ninguém é, propriamente falando, seu titular; e, no entanto, ele sempre se exerce em determinada direção, com uns de um lado e outros do outro; não se sabe ao certo quem o detém; mas se sabe quem não o possui" (FOUCAULT, 2019, p. 138). Esta noção de microfísica do poder dá para Foucault a possibilidade de compreender o poder dentro de instituições de normalização e de disciplinarização do mundo moderno, a saber, as escolas, as prisões, os hospitais, os asilos e os hospitais psiquiátricos. As instituições disciplinares se interligam umas às outras a partir de conexões capilares, assim como uma aranha que liga em sua teia vários pontos entre si com seus fios sutis. Estes fios seriam estas relações de poder a qual a análise microfísica busca compreender.

Dentro de cada uma destas instituições vemos que há um saber que as justifica; um saber proveniente da pedagogia, um saber proveniente do direito, um saber proveniente da medicina ou da psiquiatria etc., criando assim uma articulação entre ciência e saber com o poder. Nas palavras de Foucault:

Temos antes que admitir que o poder produz saber (e não simplesmente favorecendo-o porque o serve ou aplicando-o porque é útil); que poder e saber estão diretamente implicados; que não há relação de poder sem constituição correlata de um campo de saber, nem saber que não suponha e não constitua ao mesmo tempo relações de poder. Essas relações de "poder-saber" não devem então ser analisadas a partir de um sujeito do conhecimento que seria ou não livre em relação ao sistema do poder; mas é preciso considerar ao contrário que o sujeito que conhece, os objetos a conhecer e as modalidades de conhecimentos são outros tantos efeitos dessas implicações fundamentais do poder e de suas transformações históricas (FOUCAULT, 2014, p. 31).

No presente artigo, analisaremos especificamente o saber médico articulando-se com o poder institucional do Estado e em que sentido se direciona esta articulação, resgatando alguns exemplos históricos dados pelo próprio Foucault para compreender como a medicina se modificou e como as epidemias corroboraram para as modificações nesta articulação entre medicina e política que chamaremos aqui de anátomopolítica, pois o saber sobre os corpos também servirá para discipliná-los, como aponta Foucault em Vigiar e punir (2014) e como veremos no decorrer deste texto.

\section{O surgimento da medicina moderna}

Foucault ao longo de seu trabalho teórico fará várias "histórias": da loucura, da clínica, das ciências humanas, das prisões e da sexualidade. Em sua obra intitulada O nascimento da clínica (2003), publicada originalmente em 1963, o filósofo francês buscou fazer uma arqueologia da ciência médica na transição do século XVIII para o século XIX, isto é, buscar compreender quais elementos discursivos estariam por trás da mudança ocorrida dentro do saber médico de uma ciência baseada em uma nosologia, isto é, em uma classificação das patologias sem levar em conta o próprio corpo do doente para uma ciência baseada na dissecação de cadáveres com o objetivo de compreender o funcionamento do organismo e da vida.

Esse trabalho foi para Foucault uma história do "olhar" médico (coup d'oeil). Por isso, ele inicia $O$ nascimento da clínica com a seguinte frase: "Este livro trata do espaço, da linguagem e da morte; trata de olhar" (FOUCAULT, 2003, p. VII). Para se entender a mudança do olhar do médico entre a medicina dos séculos XVII e XVIII, que ele denomina de medicina das espécies ou clássica, e a medicina do século XIX, que ele denomina de medicina moderna ou clínica e que está fundamentada no estudo dos mortos para se 
compreender os vivos.

Para entender as características destes dois tipos de olhares que separam a medicina do século XVIII da medicina do século XIX, deve-se buscar qual saber estava por trás de cada uma delas e que tentava garantir a sua objetividade científica. A primeira estava baseada na História Natural, ciência que tinha como papel preponderante a classificação dos seres vivos em espécies, gêneros, famílias, ordens, classes e reinos a partir das características visíveis e externas, sendo Lineu seu principal percursor . De acordo com Branco:

A medicina clássica também foi chamada classificatória por Foucault, porque ela seguia o modelo da História Natural, conforme proposto por Lineu, em que todos os seres vivos deveriam ser classificados em nome, teoria, gênero, espécie e atributos. Assim como nos mostruários de animais ou nos jardins de plantas para organização da taxinomia, as doenças eram representadas em quadros naturais de distribuição nos gabinetes médicos. Interessante observar que as doenças eram compreendidas como entidades ideais, com suas características naturais próprias, entidades que poderiam se inserir no organismo vivo e produzir as morbidades. Diagnosticar era, portanto, decifrar e classificar a doença e localizá-la no quadro das espécies, sendo que esse quadro nosológico era meio de formalizar um diagnóstico. Era preciso articular os achados concomitantes e encontrar homologias para concluir a classificação (BRANCO, 2018, f. 45).

A medicina das espécies busca fazer uma classificação das doenças a partir dos signos que ela demonstra ao médico. Estes signos a serem interpretados são os sintomas, que podem aparecer em diferentes doenças assim como as mesmas letras podem aparecer em diferentes palavras. O médico é um leitor e a doença é o seu texto a ser interpretado, por exemplo, a febre não poderia ser classificada enquanto uma doença, pois terá várias causas e doenças que podem causá-la, sendo então a febre um signo-sintoma. "Signos e sintomas são e dizem a mesma coisa: com a única diferença que o signo dir a mesma coisa que é precisamente o sintoma” (FOUCAULT, 2003, p. 105). Esses sintomas só poderão tornar-se símbolos a partir da intervenção do médico que é seu intérprete: “O sintoma se torna, portanto, signo sob um olhar sensível à diferença, à simultaneidade ou à sucessão, e à frequência” (FOUCAULT, 2003, p. 106).

Com a passagem do século XVIII para o século XIX, há uma ruptura epistemológica nos fundamentos discursivos dos saberes entre esses séculos. Foucault chama esses fundamentos de epistémês, que funcionariam como condições de possibilidade dos saberes em uma determinada época e determinada cultura. Por exemplo, a epistémê que fundamenta os saberes dos séculos XVII e XVIII, onde a História Natural está situada, é a epistémê da representação, pois torna-se o papel das palavras representarem os objetos, por isso, o estudo dos seres vivos será na ordem da classificação. Enquanto que o século XIX terá um fundamento histórico-discursivo da temporalidade e da historicidade do ser, surgindo assim ciências que substituirão as anteriores, que no caso da substituta da História Natural será a Biologia. O autor em As palavras e as coisas afirma:

[a epistémê] é aquilo que, numa dada época, recorta na experiência um campo de saber possível, define o modo de ser dos objetos que aí aparecem, arma o olhar cotidiano de poderes teóricos e define as condições em que se pode sustentar sobre as coisas um discurso reconhecido como verdadeiro. $\mathrm{O}$ a priori histórico que, no século XVIII, fundou as pesquisas ou os debates sobre a existência dos gêneros, a estabilidade das espécies, a transmissão dos caracteres através das gerações, é a existência de uma história natural: organização de um determinado visível como domínio do saber, definição das quatro variáveis da descrição, constituição de um espaço de vizinhanças onde todo indivíduo, qualquer que seja, pode vir localizar-se (FOUCAULT, 2007, p. 219).

$\mathrm{Na}$ visão foucaultiana, houve uma descontinuidade entre a História Natural e sua substituta, a 
Biologia. Enquanto a primeira estudava os seres vivos, agora a Biologia estudará um conceito que não existia na epistémê anterior: a vida ${ }^{1}$. Com a criação do microscópio e a ousadia de Cuvier que decidiu dissecar os animais para compreender a organização dos órgãos internos dos animais, a História Natural vai sendo substituída pela Biologia. O método naturalista da classificação dos seres vivos a partir de suas características externas começa a ser substituído pelo método biológico do estudo do funcionamento interno da vida:

Um dia, no final do século XVIII, Cuvier saqueará os frascos do Museu, quebrá-los-á e dissecará toda a grande conserva clássica da visibilidade animal. Esse gesto iconoclasta, ao qual Lamarck jamais se decidirá, não traduz uma curiosidade nova por um segredo a cujo propósito não se teria tido nem a preocupação nem a coragem, nem a possibilidade de conhecer. Trata-se, muito mais seriamente, de uma mutação no espaço natural da cultura ocidental: o fim da história, no sentido de Tournefort, de Lineu, de Buffon, de Adanson, no sentido igualmente em que Boissier de Sauvages a entendia quando opunha o conhecimento histórico do visível ao filosófico do invisível, do oculto e das causas (FOUCAULT, 2007, p. 189).

A noção de epistémê de Foucault não significa que não haja divergências teóricas dentro de um momento histórico, mas que todas as divergências teóricas que existem em um determinado momento, por mais diferentes que sejam, fundamentam-se em uma condição de possibilidade discursiva e a priori, pois a epistémê é a condição de possibilidade dos saberes de uma época específica.

A nova Biologia conseguiu dar à medicina um novo modelo de positividade que substituía o estudo de manuais da nosologia da medicina das espécies. Agora, a compreensão de vida: quais são as suas necessidades para sua existência, seus sistemas internos e suas relações com o funcionamento externo do organismo, onde estão localizadas as doenças, fazendo possível uma "geografia das doenças", isto é, uma nosografia etc. Em resumo, a anatomia patológica será a responsável por tornar aquilo que era invisível aos olhos do médico agora visível, criando assim uma modificação epistêmica significativa. Nas palavras de Foucault:

O que se modifica, fazendo surgir a medicina anátomo-clínica, não é, portanto, a simples superfície de contato entre o sujeito cognoscente e o objeto conhecido; é a disposição mais geral do saber, que determina as posições recíprocas e o jogo mútuo daquele que deve conhecer e daquilo que é cognoscível. O acesso do olhar médico ao interior do corpo doente não é a continuação de um movimento de aproximação que teria se desenvolvido, mais ou menos regularmente, a partir do dia em que o olhar, que começava a ser científico, do primeiro médico se dirigiu, de longe, ao corpo do primeiro paciente; é o resultado de uma reformulação ao nível do próprio saber e não ao nível dos conhecimentos acumulados, afinados, aprofundados, ajustados (FOUCAULT, 2003, p. 156-157).

Esse novo olhar biológico e médico que descobre a vida e o corpo do homem só foi possível dentro desta epistémê da temporalidade, da finitude e da historicidade que são características dos saberes do século XIX até os dias de hoje. Essa noção de perecimento dos seres vivos torna o conceito de vida uma espécie de "ontologia selvagem", ou seja, todos os seres vivos são passageiros e daí a importância para a Biologia e

1 “Pretende-se fazer histórias da biologia no século XVIII; mas não se tem em conta que a biologia não existia e que a repartição do saber que nos é familiar há mais de 150 anos não pode valer para um período anterior. E que, se a biologia era desconhecida, o era por uma razão bem simples: é que a própria vida não existia. Existiam apenas seres vivos e que apareciam através de um crivo do saber constituído pela história natural" (FOUCAULT, 2007, p. 174175).

2 "A experiência da vida apresenta-se, pois, como a lei mais geral dos seres, o aclaramento dessa força primitiva a partir da qual eles são; ela funciona como uma ontologia selvagem que buscasse dizer o ser e o não-ser indissociáveis de todos os seres. Mas essa ontologia desvela menos o que funda os seres do que o que os leva, por um instante, a uma forma precária e secretamente já os mina por dentro, para os destruir. Em reação à vida, os seres não passam 
a medicina a compreensão de seu revés: a morte. Segue as palavras do filósofo francês:

A vida, a doença e a morte constituem agora uma trindade técnica e conceitual. A velha continuidade das obsessões milenares que colocava, na vida, a ameaça da doença e, na doença, a presença aproximada da morte é rompida: em seu lugar, se articula uma figura triangular, de que o cume superior é definido pela morte. É do alto da morte que se podem ver e analisar as dependências orgânicas e as sequências patológicas. Em lugar de permanecer o que tinha sido durante tanto tempo, noite em que a vida se apaga e em que a própria doença se confunde, ela é dotada, de agora em diante, do grande poder de iluminação que domina e desvela tanto o espaço do organismo quanto o tempo da doença... O privilégio de sua atemporalidade, que é sem dúvida tão velho quanto a consciência de sua imanência, torna-se, pela primeira vez, instrumento técnico que permite a apreensão da verdade da vida e da natureza de seu mal. A morte é a grande analista que mostra as conexões, desdobrando-as, e explode as maravilhas da gênese no rigor da decomposição: e é preciso deixar à palavra decomposição todos os pesos de seu sentido. A Análise, filosofia dos elementos e de suas leis, encontra na morte o que em vão tinha procurado nas matemáticas, na química e na própria linguagem: um modelo insuperável e prescrito pela natureza; o olhar médico vai, a partir de então, apoiar-se neste grande exemplo. Não mais o de um olhar vivo, mas de um olhar que viu a morte. Grande olho branco que desfaz a vida (FOUCAULT, 2003, p. 165).

A prática clínica então passa a se basear não em manuais nosológicos, mas na abertura de cadáveres. A prática da dissecação, como aponta Mandressi (2008), não foi uma descoberta moderna, sendo as primeiras documentalmente constatadas em Alexandria no século III a.C. e esta prática foi retomada no final da Idade Média, mesmo após a Igreja Católica tornado esta prática ilegal.

O documento histórico que Mandressi (2008) faz referência da proibição da dissecação é o Detestande feritatis, emitida pelo Papa Bonifácio VIII, em 1299, onde se declarava a posição da Igreja contrária à retaliação de cadáveres que era utilizada para facilitar o transporte dos defuntos para as sepulturas distantes do local da morte, um "costume atroz" que o Papa da época queria pôr um fim. Entretanto, o primeiro testemunho histórico explícito trazido por Mandressi (2008) é o de Mondino de’Liuzzi, de 1316, professor em Bolonha e autor de uma Anathomia, e onde ele afirma ter dissecado duas mulheres mesmo após a decretação da Detestande feritatis.

Mandressi (2008) sugere que mesmo com o decreto do Papa Bonifácio VIII a prática da dissecação no século XIV não foi extinta, mas passa a ser algo feito às escondidas pelos médicos e cirurgiões. A suposição do autor é que a proibição provinha de um argumento teológico: "a questão da integridade do corpo em relação ao dogma da ressurreição dos mortos” (MANDRESSI, 2008, p. 413), isto é, a crença de que a ressurreição dos mortos será tanto do corpo e da alma e, por isso, o corpo deve permanecer em perfeitas condições, nem mutilado e nem aberto. Essa crença pode ter impedindo o desenvolvimento da ciência anatômica.

Foucault (2003) reconhece que as dissecações já existiam na Idade Clássica e antes dela, mas foi Bichat que, segundo ele, mesmo sem o microscópio, fez uma análise do corpo de forma "diagonal”, descrevendo o corpo em camadas: órgãos, membranas serosas, fáscias fibrosas, membranas internas mucosas e glandulares etc. Os órgãos são formados pelas diferentes combinações entre os tecidos que poderíamos decompor as partes para analisá-las. Segundo Foucault, este método de Bichat nada mais é do que a aplicação

de figuras transitórias e o ser que eles mantêm, durante o episódio de sua existência, nada mais é que sua presunção, sua vontade de subsistir. De sorte que, para o conhecimento, o ser das coisas é ilusão, véu que se deve rasgar, para se reencontrar a violência muda e invisível que os devora na noite. A ontologia do aniquilamento dos seres vale, portanto, como crítica do conhecimento; mas trata-se menos de fundar o fenômeno, de dizer ao mesmo tempo seu limite e sua lei, de reportá-lo à finitude que o torna possível, do que de dissipá-lo e destruí-lo como a própria vida destrói os seres pois todo o seu ser é só aparência" (FOUCAULT, 2007, p. 384s). 
do método filosófico à medicina. "Bichat fundamentou sua nosografia, ordenando e classificando as doenças segundo as alterações comuns e gerais, ou as regionais e particulares dos tecidos, dando importância à geografia dos órgãos” (BRANCO, 2018, p. 76). De acordo com Mandressi:

Ora, escrutar cadáveres com ajuda do escalpelo não é necessariamente uma evidência fora de um tempo e de um espaço que viram este ato tornar-se a chave das operações de desnudar "verdades" do corpo. Temos o direito de presumir que a outros tempos correspondem outras evidências, e que, se durante longos séculos as dissecações não foram praticadas, é principalmente porque elas não foram julgadas necessárias. Podemos, portanto, considerar o acesso às dissecações como uma invenção, uma resposta que, num determinado momento, apareceu como adequada ou vantajosa diante da exigência de obter ou de perfazer um novo conhecimento sobre o corpo (MANDRESSI, 2008, p. 416).

Em suma, entre os séculos XVIII e XIX houve uma mudança a ordem do saber em que o conhecimento classificatório dos seres vivos da História Natural foi substituído pelo estudo da vida, isto é, a Biologia, possibilitando a mudança do "olhar" da medicina moderna, fundamentada primeiramente em uma ciência da classificação para ordenar em grupos e em quadros as doenças através da interpretação dos sintomas enquanto signos. Em seguida, a medicina fundamentou-se no surgimento da Biologia e sua "descoberta" da vida para começar a compreender o funcionamento orgânico interno e externo, dando a possibilidade à medicina de fazer com que o estudo do corpo morto lance luz sobre o corpo vivo, tornando a medicina uma prática anátomo-clínica. A dissecação dos cadáveres será, na transição do século XVIII ao XIX, a prática que garantirá a positividade da ciência médica.

\section{A medicina enquanto política de saúde pública}

Apresentada a mudança deste olhar que tornou possível o surgimento da medicina moderna nos fins do século XVIII, far-se-á necessário agora entender as condições sociais e políticas que favoreceram esta mudança, pois torna-se impossível, sob um olhar foucaultiano, compreender essa mudança epistemológica olhando para a medicina em si mesma. Ainda em O nascimento da clínica, Foucault (2003) reconhece que há por trás desta passagem da medicina das espécies para a medicina anátomo-clínica uma "consciência política", favorecida por um breve momento de transição que o autor chama de "medicina das epidemias", ou seja, aquela que se torna uma política de Estado para controle de eventuais epidemias ou endemias recorrentes em determinados lugares e em determinadas épocas. De acordo com o próprio Foucault:

A medicina das epidemias se opõe a uma medicina das classes, como a percepção coletiva de um fenômeno global, mas único e nunca repetido, pode se opor à percepção individual daquilo que uma essência pode constantemente revelar de si mesma e de sua identidade na multiplicidade dos fenômenos. Análise de uma série, em um caso, decifração de um tipo, no outro; integração do tempo, nas epidemias, definição de um lugar hierárquico, para as espécies; determinação de uma causalidade -, pesquisa de uma coerência essencial; percepção desligada de um espaço histórico e geográfico complexo - definição de uma superfície homogênea em que se leem analogias. E no entanto, no final das contas, quando se trata das figuras terciárias, que devem distribuir a doença, a experiência médica e o controle do médico nas estruturas sociais, a patologia das epidemias e a das espécies se encontram diante das mesmas exigências: a definição de um estatuto político da medicina e a constituição, ao nível de um Estado, de uma consciência médica, encarregada de uma tarefa constante de informação, controle, e coação; exigências que "compreendem objetos tanto relativos à polícia, quanto propriamente da competência médica" (FOUCAULT, 2003, p. 28). 
Essa medicina das epidemias irá se opor à medicina classificatória e individual, buscando as causas das doenças, seus modos de manifestação e de contaminação de toda uma população, associando-se às políticas de Estado que descobriu o corpo social e deu-lhe o nome de "população" e que a medicina será a responsável por cuidar da saúde deste corpo social. Segundo Branco (2018, p. 117): "Foi a medicina das epidemias que possibilitou o fortalecimento deste espaço que vai da percepção do doente às medidas do Estado".

Ora, deve-se imaginar que no sistema capitalista, a medicina tornou-se uma atividade individual, pois está ligada à economia capitalista, tornando a relação entre médico e paciente somente uma atividade financeira e que ignora a dimensão social, mas a hipótese de Foucault é oposta. Segundo ele, a medicina tornouse uma estratégia política estatal e institucional que ele chamará de biopolítica:

Minha hipótese é que com o capitalismo não se deu a passagem de uma medicina coletiva para uma medicina privada, mas justamente o contrário; que o capitalismo, desenvolvendo-se em fins do século XVIII e início do século XIX, socializou um primeiro objeto que foi o corpo enquanto força de produção, de trabalho. O controle da sociedade sobre os indivíduos não se opera simplesmente pela consciência ou pela ideologia, mas começa no corpo, com o corpo. Foi no biológico, no somático, no corporal que, antes de tudo, investiu a sociedade capitalista. O corpo é uma realidade biopolítica. A medicina é uma estratégia biopolítica3 (FOUCAULT, 2019, p. 144).

Compreende-se como biopolítica toda estratégia de gestão dos corpos de uma população: status de saúde geral de um povo, longevidade, densidade populacional, surtos de doenças, realocação geográfica de uma população, quarentenas para evitar surtos endêmicos, epidêmicos ou pandêmicos etc. O conceito de biopolítica será mais delineado em Foucault no primeiro volume da História da sexualidade, intitulado $A$ vontade de saber. Segundo Foucault (1976), a biopolítica dá ao Estado o direito de decidir quem deve morrer e o poder sobre a vida de sua população (Droit de mort et pouvoir sur la vie) e possui um desenvolvimento histórico duplo:

Concretamente, esse poder sobre a vida se desenvolveu desde o século XVII em duas formas principais; eles não são antitéticos; antes, eles constituem dois polos de desenvolvimento ligados por todo um feixe intermediário de relacionamentos. Um dos polos, ao que parece, estava centrado no corpo enquanto uma máquina: seu treinamento, o aprimoramento de suas habilidades, a extorsão de suas forças, o crescimento paralelo de sua utilidade e docilidade, sua integração em sistemas de controle eficientes e econômicos, tudo isso foi assegurado por procedimentos de poder que caracterizam as disciplinas: anátomopolíticas do corpo bumano. A segunda, que se formou um pouco mais tarde, por volta de meados do século XVIII, está centrada nas espécies corporais, no corpo atravessado pela mecânica dos vivos e que serve de suporte aos processos biológicos: proliferação, nascimentos e mortalidade, nível de saúde, expectativa de vida, longevidade com todas as condições que podem fazê-las variar; assumir o controle deles é alcançado através de uma série de intervenções e controles regulatórios: uma biopolítica da população. As disciplinas do corpo e os regulamentos da população constituem os dois polos centrais dos quais a organização do poder sobre a vida foi implantada. A implementação durante a era clássica dessa grande tecnologia de dupla face - anatômica e biológica, individualizando e especificando, voltada para o desempenho do corpo e olhando para os processos da vida - caracteriza um poder cuja função mais alta doravante talvez não mais para matar, mas para investir na vida completamente4 (FOUCAULT, 1976, p. 182s).

3 Grifos nosso.

4 Tradução livre para “Concrètement, ce pouvoir sur la vie s'est développé depuis le XVIle siècle sous deux formes principales; elles ne sont pas antithétiques; elles constituent plutôt deux pôles de développement rélies par tout um faisceau intermédiare de relations. L'un des pôles, le premier, semble-t-il, à s'être formé, a été centré sur le corps comme machine: son dressage, la majoration de ses aptitudes, l'extorsion de ses forces, la croissance parallèle de 
O aparecimento da medicina moderna coincide com a consolidação do Estado moderno que, de diferentes formas, utilizou estratégias e práticas de saúde para promover o aumento da vitalidade de sua população. Foucault (2019) chega a caracterizar três formas históricas diferentes de biopolítica no século XVIII na Europa desenvolvidas pela medicina social. Na Prússia, o primeiro Estado moderno e anterior à Alemanha unificada, vê-se uma medicina social do Estado centralizado; na França, a medicina social surge da preocupação da organização urbana de uma população que passou por uma explosão demográfica no final do século XVIII e teve que começar a se preocupar com a organização espacial das pessoas por classes social - bairros de ricos e bairros de pobres ${ }^{5}$ - locais onde deveriam estar os cemitérios e os hospitais etc.; e por último, mas não menos importante, a Inglaterra que produziu uma medicina social preocupada com a produção da força de trabalho, uma medicina na qual o alvo era o proletariado pobre, que trabalharia nas fábricas para a Revolução Industrial (1750-1860). Na segunda metade do século XIX, Foucault (2019) afirma, que a ciência do Estado alemã (Staatswissenchaft), a qual podemos chamar esta ciência hoje de demografia, criou uma polícia médica para cuidar de sua população (Medizinichepolizę) que consiste em quatro passos.

O primeiro passo seria uma observação mais detalhada de dados além das taxas de natalidade ou de mortalidade. Um registro de diferentes fenômenos epidêmicos ou endêmicos observados. O segundo seria deixar às universidades e à corporação de médicos decidir de quem será a responsabilidade atribuir os diplomas e normalizar a profissão médica. A medicina e o médico tornaram-se os primeiros indivíduos normalizados na Alemanha ${ }^{7}$. O terceiro, a criação de uma organização administrativa para controlar as atividades dos médicos, causando a subordinação da prática médica à autoridade do Estado, primeiramente na Prússia e posteriormente em outros Estados germânicos. E, por fim, mas não menos importante, a criação de funcionários médicos nomeados pelo governo com responsabilidade sobre uma região ou um distrito, seu domínio de poder ou de exercício de autoridade de seu saber. Aparece aqui então o médico como o administrador de saúde.

O objetivo dessas estratégias é a produção de saúde da população de um modo geral desde os séculos XVIII e XIX até a quarentena dos dias de hoje, mediante a punição quem ousar infringir estas medidas biopolíticas. Mesmo que isso signifique, paradoxalmente, a condenação à morte de uns em primazia da saúde

son utilité et de sa docilité, son intégration à des systèmes de controle efficaces et économiques, tout cela a été assuré par des procédures de pouvoir qui caractérisent les disciplines: anatomo-politique du corps humain. Le second, qui s'est formé um peu plus tard, vers le milieu du XVIIIle siècle, est centré sur corps-espéce, sur le corps traversé par la méchanique du vivant et servant de support aux processus biologiques: la prolifération, les naissances et la mortalité, le niveau de santé, la durée de vie, la longévité avec toutes les conditions qui peuvent les faire varier; leur prise en charge s'ópere par toute une série d'interventions et de contrôles régulateurs: une bio-politique de la population. Les disciplines du corps et les régulations de la population constituent les deux pôle autor desqueles s'est déployée l'organisation du pouvoir sur la vie. La mise en place au cours de l'âge classique de cette grande technologie à double face - anatomique et biologique, individualizante et spécifiante, tournée vers les performances du corps et regardant vers les processos de I avie - caractérise un pouvoir dont la plus haute fonction désormais n'est peut-être plus tuer mais d'investir la vie de part en part" (FOUCAULT, 1976, p. 183).

5 "A coabitação em um mesmo tecido urbano de pobres e ricos foi considerada um perigo sanitário e político para a cidade, o que ocasionou a organização de bairros pobres e ricos, de habitações ricas e pobres. 0 poder político começou então a atingir o direito da propriedade e da habitação privadas. Foi esse o momento da grande redistribuição, no II Império Francês, do espaço urbano parisiense" (FOUCAULT, 2019, p. 166).

6 Foucault ao dizer Estado alemão está se referindo especificamente ao Estado da Prússia do século XVIII.

7 Sobre o surgimento das Academias, hospitais-escolas e cursos universitários de medicina criados por políticas de Estado ver: FOUCAULT, 2003. p. 80s. Especificamente sua explanação acerca da reforma clínica e como ela está associada à reforma educacional dos cursos de medicina e da prática médico-política. 
coletiva de todos. Em Vigiar e punir (2014), Foucault resgata um regulamento do Archives militaires de Vincen$n e s^{8}$ que instaura a vigilância disciplinar da quarentena como forma de combate à peste, restringindo o contato social, mediante à pena de morte para quem descumprir a quarentena:

Em primeiro lugar, um policiamento espacial estrito: fechamento, claro, da cidade e da "terra", proibição de sair sob pena de morte, fim de todos os animais errantes; divisão da cidade em quarteirões diversos onde se estabelece o poder de um intendente. Cada rua é colocada sob a autoridade de um síndico; ele a vigia; se a deixar, será punido de morte. No dia designado, ordena-se todos que se fechem em suas casas: proibido sair sob pena de morte. O próprio síndico vem fechar, por fora, a porta de cada casa; leva a chave, que entrega ao intendente de quarteirão; este a conversa até o fim da quarentena. Cada família terá feito suas provisões; mas para o vinho e o pão se terá preparado entre a rua e o interior das casas pequenos canais de madeira, que permitem fazer chegar a cada um sua ração, sem que haja comunicação entre os fornecedores e os habitantes; para a carne, o peixe e as verduras, utilizam-se roldanas e cestas. Se for absolutamente necessário sair das casas, tal se fará por turnos, e se evitando qualquer encontro. Só circulam os intendentes, os síndicos, os soldados da guarda e também entre as casas infectadas, de um cadáver ao outro, os "corvos", que tanto faz abandonar à morte: é "gente vil, que leva os doentes, enterra os mortos, limpa e faz muitos ofícios vis e abjetos". Espaço recortado, imóvel fixado. Cada qual se prende a seu lugar. E, no caso se mexa, corre perigo de vida, por contágio ou punição (FOUCAULT, 2014, p. 190).

Segundo Byung-Chul Han (2020), a pandemia de 2020 causada pelo SARS-COV-2 indicou o retorno a essa experiência disciplinar narrada por Foucault no excerto acima, afirmando que o controle desta pandemia se tornou menos difícil pelo caráter mais autocrático dos regimes políticos orientais em face aos regimes neoliberais ocidentais". Segundo o filósofo coreano: "Regimes autoritários ensinam pessoas a serem sujeitos disciplinados e obedientes. Todas essas peculiaridades dos asiáticos provam ser vantagens do sistema em conter a epidemia" (HAN, 2020). A nossa opinião é que a sociedade disciplinar, descrita por Foucault em Vigiar e punir, ainda continua em vigor nas sociedades democráticas ocidentais, mas de forma mais sutil do que em regimes totalitários e a pandemia do Covid-19 demonstrou como a disciplinarização dos indivíduos também faz parte da biopolítica ocidental do século XXI.

Conclui-se então que a quarentena, no século XVII ou no século XXI, é uma medida política instalada pelo Estado que segue as recomendações higiênicas e sanitárias da medicina moderna, articulando assim o saber médico e o poder institucional e/ou estatal, visando o combate das epidemias. A quarentena é uma medida de uma medicina social, ou melhor, de uma estratégia biopolítica. Como demonstrado por Branco (2018) no excerto que se segue, medidas sociais tomadas hoje em prol da saúde coletiva foram tomadas anteriormente:

Aparecem instituições, no nível do Estado, que irão regulamentar o exercício social da medicina: a polícia sanitária e a Sociedade Real de Medicina. A polícia sanitária tinha funções de fiscalização da salubridade das instalações, do comércio, dos cemitérios, etc., em todo o território da província; também funções educacionais, porque deveria orientar as pessoas desde o modo de se vestir, de se alimentar, como agir para evitar e curar as doenças; e, por fim, tinha como tarefa controlar o trabalho dos médicos. A Sociedade Real de Medicina, criada por um decreto de 1776, e composta por médicos, cujo principal mentor fora Vicq d'Azyr, tinha o papel de estudo amplo das epidemias, elaboração dos fatos, controle e

8 Foucault afirma que este regulamento assemelhasse a tantos outros da mesma época ou de períodos anteriores.

9 "Apesar do neoliberalismo, os Estados asiáticos, ao contrário do Ocidente, permaneceram como sociedades disciplinares. A coletividade diretamente vinculada à disciplina predomina na Ásia. Medidas disciplinares radicais são mais fáceis de ser adotadas lá do que na Europa, porque são vistas menos como limitações aos direitos individuais e mais como um cumprimento de obrigações coletivas" (HAN, 2020). 
prescrição das medidas indicadas aos médicos e à população. Ela acabou se tornando o órgão oficial, com recursos e poder político, para fazer emergir uma nova consciência social da medicina (BRANCO, 2018, p. 116).

\section{Considerações finais}

Nosso objetivo com este breve artigo não foi fazer uma espécie de anacronismo histórico, nem questionar as práticas de isolamento social como ferramentas de controle do aumento de contaminação pelo vírus e como medida paliativa para evitar a superlotação de leito de hospitais, mas demonstrar que a quarentena e a epidemia não são fenômenos de exclusividades do ano de 2020. Demonstrando que o isolamento social mais do que uma medida médica e sanitária somente é uma forma de disciplinarização política dos indivíduos, confinando-os em suas casas e vigiando-os enquanto estão fora por aplicativos como a experiência sul-coreana para monitorar pessoas infectadas e controlar seu possível risco de contágio, como aponta a reportagem do El País (2020):

A tecnologia de vanguarda também permite, uma vez detectado um caso positivo, reunir todas as informações recentes sobre um doente e avisar qualquer pessoa com quem ele possa ter tido contato nos dias anteriores. As entrevistas dos infectados são comparadas e complementadas com diversos recursos, incluindo as informações do seu cartão de crédito e o reconhecimento facial nos espaços públicos graças a câmeras de segurança. As rotas são compartilhadas por um sistema nacional de SMS e, à medida que os dias passam, os itinerários e a análise dos minutos vão se tornando mais exaustivos.

O Covid-19 pôs um empasse para o mundo capitalista pós-Guerra Fria, demonstrando que as liberdades individuais podem ser desrespeitadas pelo próprio Estado visando a manutenção da saúde coletiva. Articulando-se a medicina moderna e o poder disciplinar - agora com a ajuda de novas tecnologias de monitoramento em câmeras e até mesmo no nosso próprio aparelho celular -, a biopolítica está lutando diariamente para barrar o avanço desta pandemia. No entanto, não devemos confundir esta estratégia anátomopolítica como um ato de "bondade governamental", pois, as intenções do Estado na manutenção da vida de seus cidadãos é garantir a manutenção de uma mão-de-obra produtiva e a manutenção do sistema de produção capitalista desde o século XVIII, seja no Estado centralizador da Prússia, na França revolucionária, na Inglaterra industrial ou no mundo capitalista globalizado de 2020, a medicina torna-se uma atividade coletiva para garantir a saúde pública e, consequentemente, a mão-de-obra coletiva.

Ressaltamos que não estamos aqui nos posicionando contra o isolamento social no combate à propagação do Covid-19, mas levantando o questionamento se estas medidas de controle drásticas e da população permanecerão mesmo após o fim desta pandemia do Covid-19, pois como nos aponta a experiência sul-coreana, segundo o El País (2020), que se demonstra a mais eficaz de controle contra a pandemia: "Embora esse procedimento vá de encontro à intimidade do indivíduo, a emergência da situação prevalece sobre o debate. As prioridades neste momento são outras, inclusive para os monitorados”. Há o risco, porém, das medidas de disciplinarização e de vigilância permanecerem ou se ampliarem após o surto da atual pandemia.

\section{REFERÊNCIAS}

BRANCO, R. Michel Foucault e a medicina - sobre o nascimento da clínica moderna. Tese (Doutorado em Filosofia) - Pontifica Universidade de São Paulo. São Paulo, p. 150. 2018.

EL PAís. (2020). Coreia do Sul: contra o coronavírus, tecnologia: Outono de 2020. Acessado em 
07/04/2020 e encontrado em: https://brasil.elpais.com/internacional/2020-03-15/coreia-dosul-contra-o-coronavirus-tecnologia.html.

FOUCAULT, M. (1963). O nascimento da clínica. Tradução de Roberto Machado. 5. ed. Rio de Janeiro: Editora Forense Universitária, 2003.

. (1966). As palavras e as coisas: uma arqueologia das ciências humanas. Tradução de Salma Tannus Muchail. 9. ed. São Paulo: Martins Fontes, 2007.

. (1975). Vigiar e punir: o nascimento das prisões. Tradução de Raquel Ramalhete 42. ed. Petrópolis: Vozes, 2014. 1976.

. (1976). Historie de la sexualité I: la volonté de savoir. (1976). 1. ed. Éditions Gallimard, ; MACHADO, R. (org.). (1979). Microfísica do poder. 9. ed. São Paulo: Paz e Terra, 2019.

HAN, Byung-chun. (2020). Pandemia do coronavírus indica retorno à sociedade disciplinar: outono de 2020. Acessado em 07/04/2020 e encontrado em: https://www1.folha.uol.com.br/mundo/ 2020/04/pandemia-do-coronavirus-indica-retorno-a-sociedade-disciplinar.shtml?utm_source=facebook\&utm_medium=social\&utm_campaign=compfb\&fbclid=IwARO-3aLXyBVOeVUuO7zBoY8Ln Q-DShlsSRapTPSinB2W83IPcgzGUUCKOkk

MANDRESSI, R.; VIGARELLA G. (org.); COURTINE J. (org.); CORBIN, A. (org.). (2005). Dissecação e anatomia. In: História do corpo: 1. Da Renascença às Luzes. (2005). Tradução de Lúcia M.E. Orth. 2. ed. Petrópolis: Vozes, 2008, p. 411-440.

Artigo recebido em: 07 de abril de 2020

Artigo aceito em: 02 de julho de 2020 